\title{
Accesibilidad y visibilidad de la fotografía patrimonial sobre Andalucía en el ámbito europeo: EuropeanaPhotography
}

\author{
María-Begoña López-Ávila*, Frederik Truyen** y Jordi Alberich-Pascual* \\ * Universidad de Granada. Facultad de Comunicación y Documentación, Departamento de Información y Comunicación. \\ Granada, España \\ Correo-e: begolopez@ugr.es | ORCID iD: https://orcid.org/0000-0002-5740-1599 \\ Correo-e: jalberich@ugr.es | ORCID iD: https://orcid.org/0000-0001-6871-4614 \\ ** KU Leuven-University. Faculty of Arts, Literary Theory and Cultural Studies. Leuven, Belgium \\ Correo-e: Fred.truyen@kuleuven.be | ORCID iD: https://orcid.org/0000-0001-6291-3663
}

Recibido: 11-01-2019; 2a versión: 26-05-2019; Aceptado: 17-06-2019.

Cómo citar este artículo/Citation: López-Ávila, M. B.; Truyen, F.; Alberich-Pascual, J. (2020). Accesibilidad y visibilidad de la fotografía patrimonial sobre Andalucía en el ámbito europeo: EuropeanaPhotography. Revista Española de Documentación Científica, 43 (2), e263. https://doi.org/10.3989/redc.2020.2.1641

Resumen: El presente artículo aborda la presencia de fotografía patrimonial sobre Andalucía en EuropeanaPhotography con el fin de evaluar su accesibilidad y visibilidad en el ámbito europeo. Para ello, se realizan una serie de consultas sistemáticas que se valoran con la métrica de precisión en esta plataforma promovida por la Unión Europea para garantizar la protección y accesibilidad del patrimonio y de la memoria fotográfica europea. Los resultados obtenidos permiten determinar el porcentaje de fotografía patrimonial sobre Andalucía en Europeana, analizar su contenido temático y las instituciones proveedoras de ésta, así como ofrecer una selección de recomendaciones y propuestas de optimización de la visibilidad y el acceso a colecciones de fotografía monumental, urbana, paisajística y de tipos del ámbito andaluz.

Palabras clave: EuropeanaPhotography; Europeana; acceso online; recuperación; optimización; fotografía; documentación fotográfica; patrimonio fotográfico; fotografía monumental; Andalucía.

\section{Accessibility and visibility of the heritage photography on Andalusia at European level: EuropeanaPhotography}

Abstract: This research involved the presence of the Andalusian heritage photography on EuropeanaPhotography in order to evaluate its accessibility and visibility at European level. A series of systematic search, a number of queries about this topic and the responses are evaluated by the metric of precision. This platform is promoted by the European Union to guarantee the protection and accessibility of the European heritage and photographic memory. The results allow us to determine the rate of the heritage photography on Andalusia in Europeana, analyse their subject contents and their cultural institutions, as well as to offer a small number of recommendations and proposals to optimise the access and visibility to collections of the Andalusian monumental, urban, landscape and popular characters photography.

Keywords: EuropeanaPhotography; Europeana; online access; retrieval; optimization; photography, photographic documentation; photographic heritage; monumental photography; Andalusia.

Copyright: (c) 2020 CSIC. Este es un artículo de acceso abierto distribuido bajo los términos de la licencia de uso y distribución Creative Commons Reconocimiento 4.0 Internacional (CC BY 4.0). 


\section{INTRODUCCIÓN}

La fotografía se considera un documento de un gran valor patrimonial, así como un medio de comunicación y representación fundamental para la constitución de nuestra memoria visual. Su aparición favoreció el interés por capturar el patrimonio histórico-artístico, popularizándose en toda Europa la reproducción de vistas de monumentos, ciudades y obras de arte, convirtiéndose así en una herramienta clave para conocer otras culturas y lugares. En la España del siglo XIX numerosos fotógrafos europeos recorrieron nuestro país con tal fin. Una de las temáticas destacadas sería el conjunto de bienes inmuebles impregnados por el orientalismo característico del sur de la península. El resultado fue la creación y difusión de un extenso cuerpo iconográfico de los principales monumentos andaluces por toda Europa, convirtiendo a la fotografía de viajes decimonónica en una divulgadora de primer orden de su cultura y su patrimonio (López-Ávila, 2018b).

La era digital provoca una transformación en la percepción de la fotografía, imponiendo un cambio de modelo y actuación en la gestión de un patrimonio en constante crecimiento (BoadasRaset, 2016). En los últimos años ha aumentado la cantidad de proyectos para hacer accesibles y visibles sus colecciones fotográficas (Foix, 2011; Sánchez-Vigil, 2011; Olivera-Zaldúa y otros, 2013; Benlloch-Serrano y otros, 2014; Vega-Rosa, 2014). Conscientes del valor cultural, social e histórico del patrimonio fotográfico que atesoran, las instituciones culturales han emprendido el tratamiento digital, difusión y acceso on-line a dichos fondos (García-Cárceles, 2016; Salvador-Benítez y Sánchez-Vigil, 2016; López-Ávila, 2018a). Cuando no ha sido así, la dificultad de acceso a sus contenidos en un entorno crecientemente digital ha penalizado a estos fondos y colecciones fotográficas con su invisibilidad social (Olivera-Zaldúa, 2015).

En relación con ello, abordamos en la presente investigación la accesibilidad y visibilidad contemporánea de fotografías sobre el patrimonio andaluz en el marco de la plataforma EuropeanaPhotography, iniciativa englobada a su vez en el proyecto Europeana, promovido por la Unión Europea para garantizar la protección y accesibilidad al conjunto de la cultura europea, así como para promover su difusión y visibilidad (Concordia y otros, 2010; Purday, 2008, 2012; Mendo-Carmona y TejadaArtigas, 2014).

La colección de Europeana está formada por millones de documentos procedentes de instituciones públicas y privadas de toda Europa (Euro- peana, 2018). España, uno de los países fundadores, participa con unos cuarenta proveedores que proporcionan acceso abierto a su acervo cultural, situándose entre los primeros cuatros países proveedores de datos (Carrato-Mena, 2014; Prieto-Gutiérrez, 2014). En relación con el patrimonio fotográfico, desarrolla proyectos con la finalidad de facilitar el acceso a la memoria fotográfica europea, tales como EuroPhoto, Daguerrobase, Europeana Open Culture app, y de forma más destacada, el proyecto EUROPEAN Ancient PHOTOgraphic vintaGe repositoRies of digitAlized Pictures of Historic qualitY, más conocido como EuropeanaPhotography y considerado el proyecto más importante sobre tratamiento fotográfico en el ámbito europeo contemporáneo (EuropeanaPhotography project, 2015)

EuropeanaPhotography está conformado por colecciones procedentes de muchas de las instituciones europeas públicas y privadas más prestigiosas que colaboran en Europeana, como archivos, museos, bibliotecas y entidades fotográficas. Se desarrolló originalmente bajo la dirección de la $K U$ Leuven (Bélgica) con la participación de diecinueve socios procedentes de trece países miembros de la UE, y en la actualidad es un repositorio de más de 450.000 fotografías, cuya cronología abarca sus primeros cien años, destinado tanto a investigadores, educadores, estudiantes, y profesionales de este ámbito o de instituciones culturales, como al público en general (Bachi y otros, 2014; Truyen y Fresa, 2015; Truyen y Verbeke, 2015).

La construcción y definición de la colección de EuropeanaPhotography se articula a partir de cuatro pautas comunes que rigen la selección del conjunto de las fotografías aportadas por las instituciones proveedoras: a) la relevancia histórica, artística o social, esto es, la preferencia por imágenes que muestren la evolución de la sociedad europea y el arte de la fotografía durante sus primeros cien años; b) un criterio geográfico centrado en Europa, en sus colonias decimonónicas, y en aquellas obras realizadas por fotógrafos europeos; c) un material fotográfico complementario al existente en Europeana, con el fin de establecer una sinergia de contenidos entre ambos proyectos; y d) la búsqueda de documentos capaces de provocar un impacto visual en el espectador, la selección de fotografías de calidad, en el marco y adecuación al concepto de "masterpiece ${ }^{1 "}$ (Truyen, 2012; Truyen y Taes, 2014). El resultado es el corpus fotográfico más completo y accesible sobre la historia, la gente, los paisajes y la vida europea del siglo XIX y del primer tercio del siglo XX (Valle-Gastaminza, 2014). 


\section{OBJETIVOS Y METODOLOGÍA}

La presente investigación tiene como objetivo general evaluar la accesibilidad y visibilidad de la fotografía patrimonial sobre Andalucía en el ámbito europeo. A partir de éste, se constituyeron como específicos: a) identificar entidades culturales del ámbito europeo con fotografía sobre el patrimonio andaluz, obteniendo como referencia a Europeana por ser la plataforma digital central para el acceso al patrimonio cultural y científico de Europa; b) analizar la accesibilidad y visibilidad de la fotografía patrimonial sobre dicho entorno geográfico en EuropeanaPhotography; c) cuantificar la presencia de esta documentación en las instituciones culturales integradas en Europeana; y finalmente, d) clasificar temáticamente las imágenes de esta comunidad autónoma presentes en EuropeanaPhotography. Así mismo, y como resultado complementario del proceso del estudio desarrollado, ofrecemos una selección de propuestas de mejora en relación con problemáticas y elementos optimizables detectados en nuestro proceso de búsqueda, recuperación y acceso a fotografía patrimonial en EuropeanaPhotography.

El material principal de nuestro estudio ha sido la documentación fotográfica procedente del conjunto de instituciones integradas en EuropeanaPhotography. Debido a la diversidad de materiales presentes, se establecieron unos criterios de búsqueda y selección: a) por ámbito geográfico (Andalucía); b) por temática (lugares - las provincias andaluzas en sí, monumentos, calles, paisajes, costumbres y tipos, excluyendo retratos de estudio o de ámbito privado, reproducciones sobre artes visuales, planos, y restos arqueológicos); y c) por tipología artística (fotografía monumental, urbana, paisajística y de tipos), teniendo en cuenta los siguientes parámetros: el acceso a la colección, el interfaz, el motor de búsqueda y la recuperación de los registros fotográficos.

La metodología se ha desarrollado en diversas fases a lo largo de los últimos dos años. Primero, se inspeccionaron las posibilidades que brinda el sistema para recuperar la información deseada. Una vez recuperada la documentación, se verificó cada uno de los registros fotográficos para identificar si cumplía los criterios de selección. A continuación, la recogida de datos se realizó entre los meses de septiembre y diciembre de 2017, durante una estancia de investigación en la $K U$ Leuven (coordinadora de EuropeanaPhotography) financiada por el Ministerio de Cultura, Educación y Deporte de España (MECD). Posteriormente, en septiembre de 2018 se realizó un sondeo de los datos recogidos.
En el interfaz se introdujeron ecuaciones de búsqueda ${ }^{2}$, relativas a los objetivos establecidos en la investigación. En las búsquedas propuestas se tomaron como referencia los parámetros planteados por Cleverdon y otros (1966), basándose en la evaluación de su precisión a partir de la relevancia de los documentos recuperados. Para delimitar el marco geográfico se utilizó el término Andalucía y Andalusia, por separado, y para concretar aún más se utilizaron los términos de las provincias andaluzas: Almería, Cádiz, Córdoba, Jaén, Huelva, Granada, Málaga y Sevilla. Al estar los metadatos en 16 idiomas se recuperaron los diversos registros fotográficos identificados con el descriptor geográfico de cada una, sin que fuese necesario traducirlos.

Las ecuaciones de búsqueda planteadas combinaron los términos clave con operadores debido a ciertas ambigüedades detectadas entre ubicaciones de la comunidad autónoma y del extranjero, ya que si únicamente se introducía where:Cordoba o where:Granada se recuperaban fotografías tanto de la ciudad de Córdoba en Argentina como del país insular de América ${ }^{3}$. Sólo la incorporación de where:Andalucía con los nombres de estas dos provincias permitía resolver la problemática. El motor de búsqueda recuperó los mismos resultados introduciendo las diversas modalidades al combinarlos, incorporando paréntesis o no, ya fuese en una única ecuación: where:Andalucía and where:Málaga, (where:Andalucía) and (where:Málaga); o combinando términos sin operadores: where:Málaga, where:Andalucía.

Recuperados los resultados relativos a la consulta, se tuvo en cuenta la limitación de la visualización de los registros a un máximo de 960 . Por lo que se filtraron por cada institución, principalmente, y por autoría (incorporando la etiqueta del campo autor who:(apellidos, nombre) con el correspondiente descriptor validado por Europeana) para acotar el número de documentos y facilitar la identificación de cada uno de los ficheros fotográficos.

En la identificación de cada uno de los registros fotográficos, se validaron aquellos que se ajustaban a los criterios de selección preestablecidos, organizándolos según la provincia correspondiente y eliminando los repetidos (aparecen en más de una consulta). Así, por ejemplo, fotografías de lugares como la Puerta de Córdoba (Sevilla) y la Estación de Córdoba (Sevilla) recuperadas inicialmente en las ecuaciones de búsqueda relativas a Sevilla, a Córdoba, o a where:Andalucía and Córdoba, fueron debidamente descartadas. 
Finalmente, una vez seleccionados y clasificados los registros fotográficos relevantes por provincias, se analizaron las tendencias temáticas según la tipología artística de la fotografía y del contenido, clasificando éstos en: a) monumental, distinguiendo entre los monumentos y/o sitios históricos ${ }^{4}$ inscritos como Bienes de Interés Cultural (B.I.C.) y aquellos que no lo son tomando como referencia el Catálogo General del Patrimonio Histórico Andaluz (Junta de Andalucía, 2018); b) paisajística, correspondiente a las panorámicas o vistas de pájaro de paisajes rurales; c) urbana, relativa a las imágenes de las ciudades, sus calles y sus gentes transitando, elementos e infraestructuras de carácter urbano y lugares de interés industrial; y d) retratos de tipos y costumbres.

\section{RESULTADOS Y DISCUSIÓN}

\subsection{El acceso a la colección y el interfaz de búsqueda}

El acceso a EuropeanaPhotography se realiza a través del portal principal de Europeana (https:// classic.europeana.eu/portal/en), que ofrece dos modalidades de acceso: 1) el panel con las colecciones temáticas; y 2) un interfaz de búsqueda sencilla que filtra por imágenes, grabaciones sonoras, textos, vídeos, objetos 3D y todos los ítems. Los resultados recuperados se visualizan a modo de tabla o de listado (Tabla I).

Tabla I. Campos de los registros fotográficos según el modo de visualización

\begin{tabular}{|c|c|c|}
\hline \multirow{2}{*}{ Campos } & \multicolumn{2}{|c|}{ Visualización } \\
\cline { 2 - 3 } & Modo de tabla & $\begin{array}{c}\text { Modo de } \\
\text { listado }\end{array}$ \\
\hline $\begin{array}{c}\text { Reproducción } \\
\text { fotográfica }\end{array}$ & $\checkmark$ & $\checkmark$ \\
\hline Título & $\checkmark$ & $\checkmark$ \\
\hline $\begin{array}{c}\text { Fecha de creación } \\
\text { Creador de la } \\
\text { fotografía }\end{array}$ & $\checkmark$ & $\checkmark$ \\
\hline Breve descripción & $\checkmark$ & $\checkmark$ \\
\hline $\begin{array}{c}\text { Proveedor de datos } \\
\text { Núm. máximo de } \\
\text { resultados }\end{array}$ & 960 & $\checkmark$ \\
\hline
\end{tabular}

Los resultados se pueden refinar o filtrar por los siguientes aspectos: a) colecciones (Todas, 1914-1918, Art, Fashion, Maps and Geography, Migration, Music, Natural History, Photography y/o Sport); b) multimedia (Imagen, texto, vídeo, sonido, 3D o sólo ítems con enlace a los objetos); c) ¿puedo usarlo? (Si con atribución: PDM; CC BY; CC BY-SA; CCO. Sí con restricciones: CC BY-NC; CC BY-NC-ND; CC BY-NC-SA; CC BY-ND; con derechos de autor-permitido el uso educativo; sin derechos de autor-otras restricciones legales conocidas; sin derechos de autor-solamente uso no comercial. Sólo con permiso: con derechos de autor, con derechos de autor no evaluado; derechos reservados-acceso libre); d) país proveedor; e) idioma, f) agregador; y g) institución.

La visualización de los resultados puede ser de $12,24,36,48,72$ y 96 registros por página. No obstante, está limitada a mostrar un máximo de $960^{5}$ ficheros del total de los recuperados. Esta restricción supone un doble esfuerzo, ya que sobre los documentos obtenidos se realizan nuevas operaciones de filtración por: institución y autor, para reducir el número de resultados recuperados en la identificación de su relevancia.

\subsection{Relevancia en la recuperación de fotogra- fías sobre Andalucía}

La mayoría de los documentos recuperados satisfacen total o parcialmente las necesidades de la búsqueda planteada, específicamente al incorporar el descriptor geográfico con la etiqueta de localización where. La evaluación de la muestra de consultas realizadas resulta satisfactoria, ya que la ratio de precisión supera el 0,61 (Tabla II).

Las búsquedas ejecutadas recuperaban inicialmente 3.676 registros fotográficos al introducir el término Andalucía (sin aplicar ningún criterio). La realización posterior de consultas más exhaustivas -con incorporación de criterios de selecciónpermitió identificar un $16,89 \%$ más de fotografías sobre Andalucía.

Durante la identificación de cada uno de los registros fotográficos se obtiene toda la información sobre los descriptores utilizados en los mismos. En esta actividad se detecta que algunas de las fotografías no se identifican con la localización o el descriptor topográfico de Andalucía, ya que ocasionalmente se encuentran en otras comunidades autónomas como es el caso de un conjunto de 36 imágenes sobre Córdoba ubicadas en Castilla-La Mancha o algunas sobre Ronda (Málaga) en Asturias, entre otras. Igualmente, se da el caso opuesto con reproducciones sobre Zaragoza, Burgos, El Escorial (Madrid), La Catedral (León) referidas con el descriptor geográfico de Andalucía o alguna de sus provincias. Además, de otras fotografías que aparecen localizadas en la provincia pero no en dicha comunidad, de ahí la necesidad de combinar los diversos términos. 
Tabla II. Precisión en cada una de las consultas realizadas de la presencia de fotografía sobre Andalucía

\begin{tabular}{|c|c|c|c|}
\hline Estrategia de búsqueda (Consulta) & Total doc. recuperados & Doc. relevantes & Precisión \\
\hline where:Almería & 17 & 17 & 1 \\
\hline where:Andalucia and where:Almería & 17 & 17 & 1 \\
\hline where:Andalucia and Almería & 20 & 17 & 0,85 \\
\hline Almería & 31 & 19 & 0,61 \\
\hline where:Cádiz & 476 & 461 & 0,97 \\
\hline where:Andalucia and where:Cádiz & 455 & 455 & 1 \\
\hline where:Andalucia and Cádiz & 456 & 456 & 1 \\
\hline Cádiz & 563 & 471 & 0,84 \\
\hline where:Córdoba & 567 & 553 & 0,98 \\
\hline where:Andalucia and where:Córdoba & 484 & 479 & 0,99 \\
\hline where:Andalucia and Córdoba & 489 & 479 & 0,98 \\
\hline Córdoba & 692 & 587 & 0,85 \\
\hline where:Granada & 1.245 & 1.217 & 0,98 \\
\hline where:Andalucia and where:Granada & 1.143 & 1.138 & 1 \\
\hline where: Andalucia and Granada & 1.144 & 1.138 & 0,99 \\
\hline Granada & 1.436 & 1.313 & 0,91 \\
\hline where: Huelva & 138 & 134 & 0,97 \\
\hline where:Andalucia and where:Huelva & 134 & 134 & 1 \\
\hline where:Andalucia and Huelva & 134 & 134 & 1 \\
\hline Huelva & 155 & 143 & 0,92 \\
\hline where:Jaén & 189 & 183 & 0,97 \\
\hline where:Andalucia and where:Jaen & 189 & 183 & 0,97 \\
\hline where:Andalucia and Jaén & 189 & 183 & 0,97 \\
\hline Jaén & 219 & 187 & 0,85 \\
\hline where:Málaga & 400 & 391 & 0,98 \\
\hline where:Andalucia and where:Málaga & 356 & 355 & 0,99 \\
\hline where: Andalucia and Málaga & 357 & 355 & 0,99 \\
\hline Málaga & 455 & 419 & 0,92 \\
\hline where:Sevilla & 913 & 892 & 0,98 \\
\hline where:Andalucia and where:Sevilla & 773 & 773 & 1 \\
\hline where:Andalucia and Sevilla & 803 & 773 & 0,96 \\
\hline Sevilla & 1.381 & 1.098 & 0,80 \\
\hline
\end{tabular}

En la estrategia de búsqueda Andalucía or Andalusia el total de fotografías obtenidas se filtra, ya que algunas se encuentran identificadas con el término Andalucía, pero no corresponden a la comunidad autónoma como un barco noruego denominado "Nueva Andalucía" en el mar nórdico, Casa de Andalucía (Getafe), chabolas en La Pastora (Carretera de Andalucía, Madrid), el banco Granada (Girona), la visita de los Duques de Cádiz a las Palmas o calles denominadas con el nombre de las provincias andaluzas fuera de Andalucía, entre otras.
Por otro lado, si se introduce el término solamente de la provincia se produce una gran cantidad de ruido, por ejemplo con Granada se genera ambigüedad, recuperando fotografías del proyectil explosivo, del fruto del granado o del país insular de América. No obstante, esta ecuación de búsqueda es necesaria ya que no todos los registros fotográficos tienen identificados correctamente su ubicación o localización con los descriptores geográficos, principalmente depende de la descripción aportada por la institución de procedencia o por el proveedor. 


\subsection{Presencia de fotografías sobre Andalucía en EuropeanaPhotography}

EuropeanaPhotography recoge cerca de 4.297 fotografías sobre Andalucía, de las cuales 4.243 están identificadas con la provincia correspondiente y 54 se identifican solamente con el término Andalucía o Andalusia, que se corresponden con 17 registros fotográficos procedentes del Instituto del Patrimonio Cultural de España, 34 del Österreichische Nationalbibliothek (Austrian National Library) y 3 del United Archives que no tienen la provincia correspondiente entre sus descriptores geográficos (Tabla III).
De las cuarenta y dos entidades que generan registros relacionados con los términos propuestos, solamente un $60 \%$ aporta patrimonio fotográfico de esta comunidad autónoma. Esta reducción tan significativa se produce al combinar las ecuaciones de búsqueda (principalmente usando la etiqueta where:) y al aplicar los criterios de selección establecidos previamente. Como resultado, un total de veinticinco instituciones culturales proveen fotografías sobre Andalucía, sus monumentos y sus calles.

Tabla III. Cifras de los registros fotográficos sobre Andalucía, identificados sin y con el descriptor geográfico de la provincia, procedentes de las instituciones en EuropeanaPhotography

\begin{tabular}{|c|c|c|c|c|c|c|c|}
\hline \multirow{2}{*}{ Institución } & \multicolumn{2}{|c|}{ Ámbito } & \multirow{2}{*}{$\begin{array}{l}\text { Total colección } \\
\text { EuropeanaPhotography }\end{array}$} & \multicolumn{2}{|c|}{ Descriptor geográfico } & \multirow{2}{*}{ Total } & \multirow{2}{*}{$\%$} \\
\hline & Int. & Nac. & & $\begin{array}{l}\text { Andalucía/ } \\
\text { Andalusia }\end{array}$ & Provincias & & \\
\hline $\begin{array}{l}\text { Instituto del Patrimonio } \\
\text { Cultural de España }\end{array}$ & & $\checkmark$ & 95.656 & 17 & 3.393 & 3.410 & $3,56 \%$ \\
\hline $\begin{array}{l}\text { Col·lecció Ajuntament de } \\
\text { Girona }\end{array}$ & & $\checkmark$ & 50.917 & & 276 & 276 & $0,54 \%$ \\
\hline $\begin{array}{l}\text { Österreichische } \\
\text { Nationalbibliothek }\end{array}$ & $\checkmark$ & & 70.976 & 34 & 190 & 224 & $0,32 \%$ \\
\hline Rijksmuseum & $\checkmark$ & & 9.065 & & 182 & 182 & $2,01 \%$ \\
\hline $\begin{array}{l}\text { Biblioteca Digital Memoria de } \\
\text { Madrid }\end{array}$ & & $\checkmark$ & 3.189 & & 74 & 74 & $2,32 \%$ \\
\hline $\begin{array}{l}\text { Biblioteca Virtual de la } \\
\text { Provincia de Málaga } \\
\end{array}$ & & $\checkmark$ & 42 & & 41 & 41 & $97,62 \%$ \\
\hline United Archives & $\checkmark$ & & 11.758 & 3 & 21 & 24 & $0,20 \%$ \\
\hline $\begin{array}{l}\text { Architekturmuseum der } \\
\text { Technischen Universität } \\
\text { Berlin }\end{array}$ & $\checkmark$ & & 10.399 & & 16 & 16 & $0,15 \%$ \\
\hline $\begin{array}{l}\text { FEDAC: Archivo de Fotografía } \\
\text { Histórica de Canarias }\end{array}$ & & $\checkmark$ & 33.251 & & 12 & 12 & $0,04 \%$ \\
\hline $\begin{array}{l}\text { Museum of History of } \\
\text { Photography }\end{array}$ & $\checkmark$ & & 416 & & 6 & 6 & $1,44 \%$ \\
\hline $\begin{array}{l}\text { Generalitat: Arxiu Comarcal } \\
\text { de I'Alt Penedès }\end{array}$ & & $\checkmark$ & 1.973 & & 6 & 6 & $0,30 \%$ \\
\hline Biblioteca Ciconia & & $\checkmark$ & 35 & & 4 & 4 & $11,43 \%$ \\
\hline Bibliothèque de I'INHA & $\checkmark$ & & 4.687 & & 3 & 3 & $0,06 \%$ \\
\hline Museu Frederic Marès & & $\checkmark$ & 397 & & 3 & 3 & $0,76 \%$ \\
\hline Riksantikvarieämbetet & $\checkmark$ & & 43.889 & & 2 & 2 & $0,00 \%$ \\
\hline $\begin{array}{l}\text { Kunstbibliothek, Staatliche } \\
\text { Museen zu Berlin }\end{array}$ & $\checkmark$ & & 2.585 & & 2 & 2 & $0,08 \%$ \\
\hline $\begin{array}{l}\text { Sverresborg Trøndelag } \\
\text { Folkemuseum } \\
\end{array}$ & $\checkmark$ & & 1.728 & & 2 & 2 & $0,12 \%$ \\
\hline \begin{tabular}{|l} 
Digitales Kunst- und \\
Kulturarchiv Düsseldorf
\end{tabular} & $\checkmark$ & & 1.054 & & 2 & 2 & $0,19 \%$ \\
\hline $\begin{array}{l}\text { Colección Simone Choulle y } \\
\text { el Tallerdaguerrotipo }\end{array}$ & & $\checkmark$ & 17 & & 2 & 2 & $11,76 \%$ \\
\hline $\begin{array}{l}\text { Stadtgeschichtliches Museum } \\
\text { Leipzig }\end{array}$ & $\checkmark$ & & 35.375 & & 1 & 1 & $0,00 \%$ \\
\hline Malmö museer & $\checkmark$ & & 19.170 & & 1 & 1 & $0,01 \%$ \\
\hline Stiftelsen Nordiska museet & $\checkmark$ & & 7.928 & & 1 & 1 & $0,01 \%$ \\
\hline Norsk Teknisk Museum & $\checkmark$ & & 4.498 & & 1 & 1 & $0,02 \%$ \\
\hline Biblioteca Digital AECID & & $\checkmark$ & 174 & & 1 & 1 & $0,57 \%$ \\
\hline $\begin{array}{l}\text { Biblioteca de la Universidad } \\
\text { Complutense de Madrid }\end{array}$ & & $\checkmark$ & 45 & & 1 & 1 & $2,22 \%$ \\
\hline Total & 14 & 11 & 409.224 & 54 & 4.243 & 4.297 & $1,05 \%$ \\
\hline
\end{tabular}


La identificación de cada una de estas instituciones culturales con fotografía sobre dicho patrimonio, muestra la diversidad de tipologías que ofrecen a nivel nacional e internacional fotografía andaluza. Destacan los museos en el ámbito internacional, reflejo de la creciente adquisición de colecciones fotográficas por parte de los mismos y su fomento como promotores de la fotografía a lo largo del siglo XX. En el polo opuesto, las bibliotecas nacionales difunden este tipo de documentación, seguidas de archivos y otras tipologías culturales como los institutos de patrimonio.

La mayoría de instituciones proveedoras internacionales -frente a sólo once de procedencia española- reflejan la significativa presencia del patrimonio fotográfico sobre Andalucía en el ámbito europeo, en especial a través de la fotografía histórica de monumentos como La Alhambra (Granada), La Giralda (Sevilla) o La Mezquita (Córdoba) o de paisajes de playas malagueñas y gaditanas. Mientras la aportación sobre esta comunidad autónoma de una entidad de carácter nacional como el Instituto de Patrimonio Cultural de España es de solamente el 3,56\% de sus fotografías en EuropeanaPhotography, la contribución sobre Andalucía de una institución internacional como el Rijksmuseum (Ámsterdam, Países Bajos) supone hasta un 2,01\% de sus fondos fotográficos (Tabla III).

\subsection{Contenido temático de la fotografía an- daluza en EuropeanaPhotography}

El análisis del contenido temático de las fotografías sobre Andalucía en EuropeanaPhotogra- phy clasificadas por provincias (Figura 1) muestra un claro predominio de imágenes sobre Granada, seguida de Sevilla y Córdoba, reflejo del interés que alcanzó el triángulo Granada, Córdoba y Sevilla en la sociedad del siglo XIX (Yáñez-Polo, 1986; González-Pérez, 2017; López-Ávila, 2015, 2018b). Frente a estas tres provincias que lideran la presencia, en el polo opuesto Almería y Huelva evidencian una representación realmente escasa en EuropeanaPhotography.

A continuación, el análisis previo por provincias de cada uno de los registros fotográficos se relacionó con sus correspondientes entidades proveedoras. Así, se realizó un nuevo estudio y clasificación, que permitió identificar y mostrar la vinculación de cada temática en -principalmente- instituciones culturales de ámbito internacional (Tabla IV).

De nuevo, la provincia andaluza con mayor predominio en el ámbito europeo es la de Granada, ya que está presente en diez instituciones internacionales como el Rijksmuseum con 53 fotografías, el Österreichische Nationalbibliothek (Austrian National Library), el United Archives o el Architekturmuseum der Technischen Universität Berlin, seguida de Sevilla con 158 registros entre esas mismas entidades culturales, así como las 127 imágenes sobre Córdoba en otras instituciones como el $\mathrm{Mu}$ seum of History of Photography, el Norsk Teknisk Museum o la Bibliothèque de I'INHA, aparte de las ya citadas. Las ciudades malagueñas y gaditanas se difunden en cuatro y tres proveedoras correlativamente, incorporando el Stiftelsen Nordiska Museet entre las europeas (Tabla IV).

Figura 1. Número total de fotografías relevantes en EuropeanaPhotography presentadas por provincias

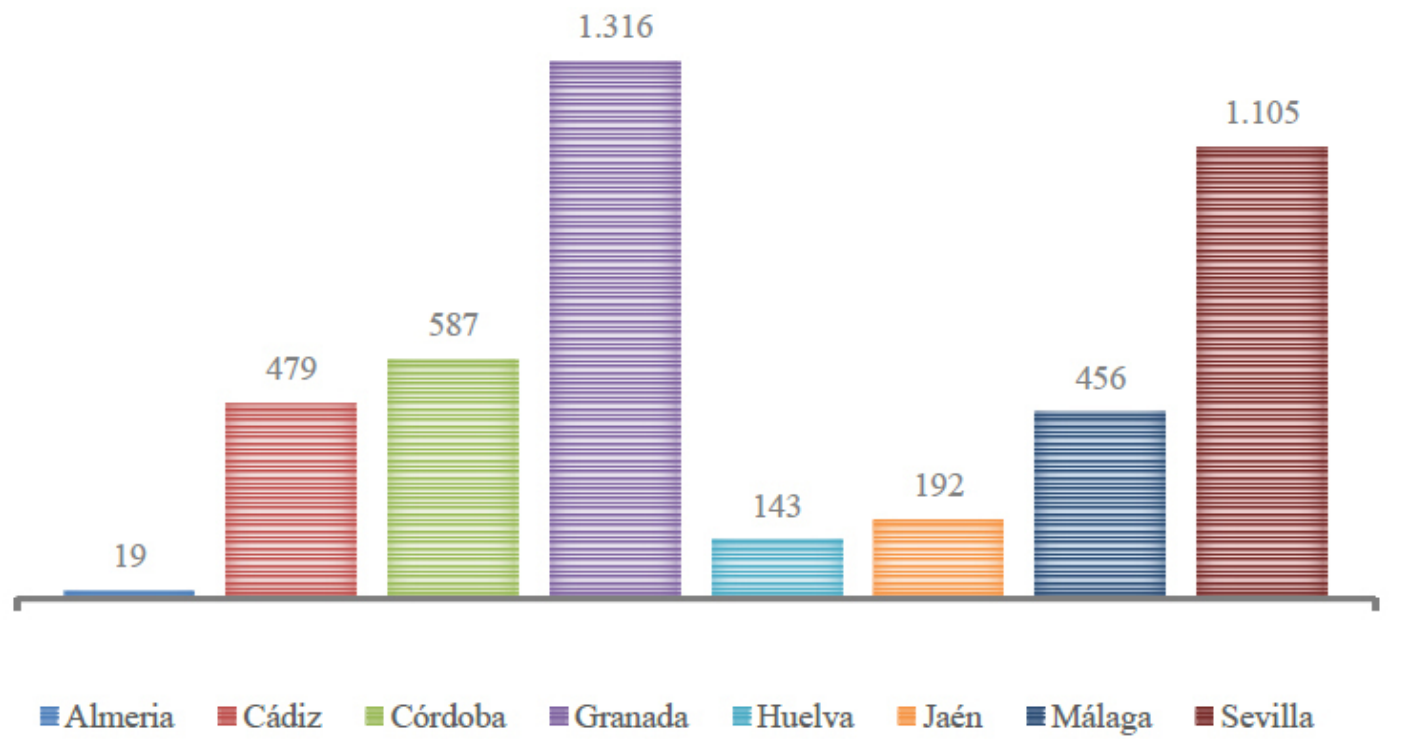


Tabla IV. Cifras de los registros fotográficos sobre Andalucía procedentes de las instituciones en EuropeanaPhotography, clasificados por la provincia

\begin{tabular}{|c|c|c|c|c|c|c|c|c|c|}
\hline \multirow{2}{*}{ Institución } & \multicolumn{8}{|c|}{ Contenido temático por provincia } & \multirow{2}{*}{ Total } \\
\hline & Almería & Cádiz & Córdoba & Granada & Huelva & Jaén & Málaga & Sevilla & \\
\hline $\begin{array}{l}\text { Instituto del Patrimonio } \\
\text { Cultural de España }\end{array}$ & 17 & 463 & 425 & 1.100 & 134 & 189 & 358 & 724 & 3.410 \\
\hline $\begin{array}{l}\text { Col-lecció Ajuntament de } \\
\text { Girona }\end{array}$ & 2 & 5 & 23 & 66 & 9 & 3 & 1 & 167 & 276 \\
\hline $\begin{array}{l}\text { Österreichische } \\
\text { Nationalbibliothek }\end{array}$ & 0 & 0 & 98 & 39 & 0 & 0 & 34 & 53 & 224 \\
\hline Rijksmuseum & 0 & 4 & 24 & 53 & 0 & 0 & 12 & 89 & 182 \\
\hline $\begin{array}{l}\text { Biblioteca Digital Memoria de } \\
\text { Madrid }\end{array}$ & 0 & 2 & 12 & 21 & 0 & 0 & 5 & 34 & 74 \\
\hline $\begin{array}{l}\text { Biblioteca Virtual de la } \\
\text { Provincia de Málaga }\end{array}$ & 0 & 0 & 0 & 0 & 0 & 0 & 41 & 0 & 41 \\
\hline United Archives & 0 & 1 & 2 & 12 & 0 & 0 & 0 & 9 & 24 \\
\hline $\begin{array}{l}\text { Architekturmuseum der } \\
\text { Technischen Universität Berlin }\end{array}$ & 0 & 1 & 0 & 9 & 0 & 0 & 0 & 6 & 16 \\
\hline $\begin{array}{l}\text { FEDAC: Archivo de Fotografía } \\
\text { Histórica de Canarias }\end{array}$ & 0 & 3 & 0 & 4 & 0 & 0 & 2 & 3 & 12 \\
\hline $\begin{array}{l}\text { Museum of History of } \\
\text { Photography }\end{array}$ & 0 & 0 & 1 & 2 & 0 & 0 & 0 & 3 & 6 \\
\hline $\begin{array}{l}\text { Generalitat: Arxiu Comarcal de } \\
\text { I'Alt Penedès }\end{array}$ & 0 & 0 & 0 & 0 & 0 & 0 & 0 & 6 & 6 \\
\hline Biblioteca Ciconia & 0 & 0 & 0 & 0 & 0 & 0 & 0 & 4 & 4 \\
\hline Bibliothèque de I'INHA & 0 & 0 & 1 & 1 & 0 & 0 & 1 & 0 & 3 \\
\hline Museu Frederic Marès & 0 & 0 & 0 & 2 & 0 & 0 & 0 & 1 & 3 \\
\hline Riksantikvarieämbetet & 0 & 0 & 0 & 2 & 0 & 0 & 0 & 0 & 2 \\
\hline $\begin{array}{l}\text { Kunstbibliothek, Staatliche } \\
\text { Museen zu Berlin }\end{array}$ & 0 & 0 & 0 & 2 & 0 & 0 & 0 & 0 & 2 \\
\hline $\begin{array}{l}\text { Sverresborg Trøndelag } \\
\text { Folkemuseum }\end{array}$ & 0 & 0 & 0 & 0 & 0 & 0 & 0 & 2 & 2 \\
\hline $\begin{array}{l}\text { Digitales Kunst- und } \\
\text { Kulturarchiv Düsseldorf }\end{array}$ & 0 & 0 & 0 & 0 & 0 & 0 & 0 & 2 & 2 \\
\hline $\begin{array}{l}\text { Colección Simone Choulle y el } \\
\text { Tallerdaguerrotipo }\end{array}$ & 0 & 0 & 0 & 0 & 0 & 0 & 0 & 2 & 2 \\
\hline $\begin{array}{l}\text { Stadtgeschichtliches Museum } \\
\text { Leipzig }\end{array}$ & 0 & 0 & 0 & 1 & 0 & 0 & 0 & 0 & 1 \\
\hline Malmö museer & 0 & 0 & 0 & 1 & 0 & 0 & 0 & 0 & 1 \\
\hline Stiftelsen Nordiska museet & 0 & 0 & 0 & 0 & 0 & 0 & 1 & 0 & 1 \\
\hline Norsk Teknisk Museum & 0 & 0 & 1 & 0 & 0 & 0 & 0 & 0 & 1 \\
\hline Biblioteca Digital AECID & 0 & 0 & 0 & 1 & 0 & 0 & 0 & 0 & 1 \\
\hline $\begin{array}{l}\text { Biblioteca de la Universidad } \\
\text { Complutense de Madrid }\end{array}$ & 0 & 0 & 0 & 0 & 0 & 0 & 1 & 0 & 1 \\
\hline Total & 19 & 479 & 587 & 1.316 & 143 & 192 & 456 & 1.105 & 4.297 \\
\hline
\end{tabular}


Finalmente, los resultados del análisis según la tipología artística de la fotografía y del contenido de cada uno de los registros, de acuerdo con la clasificación previa de éstos entre fotografía monumental (distinguiendo entre los inscritos como Bien de Interés Cultural y aquéllos que no lo son), paisajística, urbana, y retratos de tipos y costumbres, evidencian cómo la reproducción sobre monumentos B.I.C. predomina entre todas las temáticas con un $59,79 \%$ respecto al total de fotografías identificadas sobre Andalucía en EuropeanaPhotography (Tabla V).

Son Granada, Almería y Sevilla las que ofrecen un porcentaje más elevado de fotografía de este tipo monumental (B.I.C.) con un $84,27 \%, 84,21 \%$ y $82,36 \%$ respectivamente; seguidas de Córdoba con un $53,78 \%$, sobresaliendo la Mezquita Catedral y el Puente Romano. Cabe destacar la notoria presencia de patrimonio fotográfico sobre La Alhambra (Granada), alcanzando el millar de fotografías repartidas entre las instituciones colaboradoras de EuropeanaPhotography. En consonancia con este estilo arquitectónico, encontramos un predominio de los Reales Alcázares de Sevilla. En Málaga, la visualización de monumentos está muy diversificada con reproducciones sobre la Iglesia Catedral de la Encarnación (Málaga), la Alcazaba, otras iglesias de la capital malagueña, así como bienes inmuebles ubicados por sus ciudades como el Castillo de Suel en Fuengirola. Igualmente sucede en la provincia jienense con un $27,60 \%$ muy repartido entre bienes inmuebles religiosos y civiles como la Iglesia Catedral de la Asunción de la Virgen (Jaén), el Castillo La Iruela (Iruela, La) o monumentos procedentes de Baeza y Úbeda. Por otro lado, Cádiz y Huelva tienen poca representación monumental con un $16,84 \%$ y $16,50 \%$ respectivamente; sin embargo, destacan en la fotografía urbana con imágenes fotográficas sobre diferentes perspectivas de la ciudad gaditana y onubense, sus plazas, sus puertos, sus faros o lugares de interés industrial como sus centrales térmicas. En relación con la paisajística, sobresalen Jaén con un $30,73 \%$ por sus campiñas rurales y Málaga con un $22,22 \%$ ofrece panorámicas y vistas de pájaro de características zonas como Antequera o Ronda. Por último, en los retratos de tipos predominan nuevamente Granada, Córdoba y Sevilla con la recuperación de un centenar y medio de personajes vestidos a la usanza andaluza o morisca o realizando sus labores costumbristas.

\section{CONCLUSIONES}

Los resultados alcanzados muestran la accesibilidad y visibilidad de la fotografía patrimonial andaluza en el ámbito europeo a través de EuropeanaPhotography, permitiendo el acceso y la recuperación de los registros fotográficos sobre Andalucía en esta plataforma. Pese a ello, se detecta la necesidad de abordar la optimización en dicho repositorio, asignando los descriptores geográficos correspondientes, incorporando los de las entidades o denominaciones del bien representado y los de materias con carácter topográfico, añadiendo categorías temáticas en la búsqueda avanzada/filtro, ampliando la visualización del número de registros recuperados, y fomentando la incorporación de nuevas instituciones con colecciones fotográficas sobre el ámbito andaluz.

Respecto al acceso a la colección y al interfaz de búsqueda de EuropeanaPhotography, la plataforma proporciona un acceso a la información adecuado, en el que el usuario puede navegar de forma intuitiva y ergonómica, aunque con posibles mejoras como la incorporación de categorías temáticas por el contenido de la imagen fotográfica. Así mismo, la limitación en la visualización de resultados supone un inconveniente, ya que a los registros recuperados se les deben aplicar nuevas operaciones de filtración para reducir su número. Debería ampliarse el margen del total de documentos mostrados y obtenidos en cada consulta.

Tabla V. Porcentaje de las temáticas de los registros fotográficos sobre Andalucía en EuropeanaPhotography, organizados por la provincia

\begin{tabular}{|l|c|c|c|c|c|c|c|c|c|}
\hline $\begin{array}{l}\text { Temática } \\
\text { fotográfica }\end{array}$ & Almería & Cádiz & Córdoba & Granada & Huelva & Jaén & Málaga & Sevilla & Total \\
\hline $\begin{array}{l}\text { Monumental } \\
\text { (B.I.C.) }\end{array}$ & $84,21 \%$ & $16,84 \%$ & $53,78 \%$ & $84,27 \%$ & $16,50 \%$ & $27,60 \%$ & $34,38 \%$ & $82,36 \%$ & $59,79 \%$ \\
\hline Monumental & & $8,33 \%$ & $23,41 \%$ & $1,75 \%$ & $5,34 \%$ & $9,38 \%$ & $8,85 \%$ & $6,08 \%$ & $8,04 \%$ \\
\hline Paisajista & $5,26 \%$ & $6,63 \%$ & $1,63 \%$ & $2,28 \%$ & $13,11 \%$ & $30,73 \%$ & $22,22 \%$ & $0,34 \%$ & $6,31 \%$ \\
\hline Urbana & $10,53 \%$ & $66,84 \%$ & $12,44 \%$ & $6,53 \%$ & $65,05 \%$ & $26,56 \%$ & $33,68 \%$ & $6,68 \%$ & $21,56 \%$ \\
\hline Tipos & & $1,36 \%$ & $8,74 \%$ & $5,17 \%$ & & $5,73 \%$ & $0,87 \%$ & $4,54 \%$ & $4,30 \%$ \\
\hline
\end{tabular}


En relación con la relevancia en la recuperación de esta documentación fotográfica, los principales errores detectados se deben -mayoritariamente- a una asignación errónea de los descriptores geográficos: es necesario realizar una combinación de numerosas estrategias de búsqueda, para recuperar una información que se podría haber obtenido con solamente ocho consultas, where:provincia y/o where:Andalucía. Igualmente, se debe mejorar la descripción de los metadatos para evitar la omisión de fotografías sobre Andalucía, ubicadas en otras comunidades españolas o identificadas erróneamente, así como incorporar descriptores de materias con carácter topográfico para evitar la confusión del contenido temático con el geográfico (problemática frecuente en la reproducción de obras de arte relativas al ámbito andaluz).

Respecto a la presencia de la fotografía andaluza en las instituciones culturales europeas integradas en EuropeanaPhotography, se revela que el interés por este tipo de reproducciones sobre patrimonio sigue vigente actualmente en el ámbito europeo. Estas entidades aportan un porcentaje considerable de la misma, teniendo en cuenta dos aspectos, por un lado el ámbito geográfico del que se ocupan y por otro el laborioso proceso documental que implica la contribución de cada una de ellas en EuropeanaPhotography. Referente a la diversidad de tipologías institucionales, se manifiesta el carácter dispersivo de la propia imagen patrimonial. La representación de la fotografía patrimonial andaluza predomina en los museos internacionales, reflejando la integración de ésta como una obra museística y afirmando el papel difusor y promotor de esta institución cultural.

En relación con el contenido temático, se confirma el valor de la fotografía como divulgadora esencial de la cultura andaluza, que convirtió a las provincias de Granada, Sevilla y Córdoba en un destino turístico de primer orden en el ámbito internacional. Los resultados de las búsquedas sistemáticas realizadas evidencian igualmente cómo las ciudades más fotografiadas fueron Granada, Sevilla y Córdoba, y cómo los monumentos de estilos artísticos como el hispanomusulmán, nazarí, mudéjar, renacimiento, barroco y gótico despertaron el mayor interés en numeroso público europeo. Los fotógrafos extranjeros que se asentaron en Andalucía estaban interesados por La Alhambra y la cultura árabe, de ahí que el monumento B.I.C. más representado sea La Alhambra (Granada), seguido de los Reales Alcázares (Sevilla), y la Mezquita Catedral (Córdoba), mientras que las ciudades costeras como Cádiz, Huelva o Málaga se caracterizan por la fotografía urbana. En relación con la anterior conclusión, se percibe que hay cierta proximidad entre la finalidad temática de las instituciones culturales y las ciudades representadas. Cabe destacar cómo el Stiftelsen Nordiska museet (Estocolmo, Suecia), quizás por la familiaridad con ciudades costeras, ofrece alguna imagen de la ciudad malagueña, cuya presencia internacional no es muy alta.

La presencia y visibilidad de fotografía sobre Andalucía en EuropeanaPhotography aumentaría, indudablemente, con la participación de instituciones culturales tanto nacionales como internacionales con colecciones fotográficas de dicha comunidad autónoma no representadas hasta la fecha. Consideramos adecuado destacar en este sentido el interés de incorporación del Instituto Andaluz de Patrimonio Histórico (IAPH) -con un amplísimo repertorio de imágenes sobre este entorno geográfico- como proveedor a EuropeanaPhotography, así como archivos del ámbito privado o público con magníficos fondos fotográficos relativos a Andalucía ${ }^{6}$. Esta colaboración mejoraría la visibilidad tanto de esta temática como de las propias entidades a través de su presencia en una plataforma patrimonial de acceso universal como Europeana.

La optimización de EuropeanaPhotography al enriquecer el contenido de sus colecciones y al aplicar las mejoras y recomendaciones sobre descriptores, facilitará la obtención de información al usuario potencial, convirtiéndose en una herramienta imprescindible de trabajo para todo aquel profesional (o cualquier ciudadano interesado) que necesite consultar $\mathrm{y} / \mathrm{u}$ obtener documentación fotográfica europea de carácter patrimonial.

En investigaciones futuras nos proponemos llevar a cabo el análisis documental del tratamiento y procedimiento técnico de cada uno de los registros fotográficos recuperados. Así mismo, con el fin de optimizar la accesibilidad y recuperación de fotografía patrimonial en el ámbito europeo, nos proponemos la definición de un nuevo modelo de descripción ad hoc para este tipo de fotografías.

\section{AGRADECIMIENTOS}

Este trabajo ha sido financiado por el Ministerio de Educación, Cultura y Deporte de España, a través del programa de ayudas de Formación de Profesorado Universitario (FPU) 2014 (nº de referencia FPU14-04599) y el programa de ayudas a la movilidad para estancias breves 2016 ( $n^{\circ}$ de referencia EST16/00958).

\section{ACKNOWLEDGEMENTS}

This paper has been supported by the University Teacher Training Program FPU-2014 (reference number FPU14-04599) and the Temporary Research Stay Program 2016 (reference number EST16/00958) of the Ministry of Education, Culture and Sports of Spain. 


\section{NOTAS}

1. "A work done with extraordinary skill, especially a work of fine art, craft or intellect that is an exceptionally great achievement. To some, this means the best piece of work by a particular artist or craftsperson" (ArtLex Art Dictionary citado en Truyen y Taes, 2014, p. 5).

2. En la ecuación de búsqueda se utilizó un lenguaje de interrogación, incorporando operadores booleanos (or, and, not) y de anidamiento al concretar, incluir o excluir términos para ampliar o reducir los resultados; al excluir se recomienda usar guion (-) en lugar de not. Además de éstos, se introdujo el campo localización con etiqueta de lugar where: para delimitar la búsqueda por la provincia indicada como (where:Sevilla). El sistema admite introducir mayúscula o minúscula, con o sin tilde, ya que el motor de búsqueda reconoce los diversos caracteres, facilitando la búsqueda y recuperación. Igualmente permite recurrir a operadores lógicos, de anidamiento, texto libre y/o términos, campos, truncamiento, entre otros.

3. El Ethnologisches Museum, Staatliche Museen zu Berlin incorpora los descriptores geográficos relativos a Granada y Córdoba, pero añade la denominación España junto a estos. De modo que tampoco

\section{REFERENCIAS}

Bachi, V.; Fresa, A.; Pierotti, C.; Prandoni, C. (2014). The Digitization Age: Mass Culture Is Quality Culture. Challenges for Cultural Heritage and Society. En: Ioannides, M.; Magnenat-Thalmann, N.; Fink, E.; Žarnić, R.; Yen, A.Y.; Quak, E. (eds.), Digital Heritage. Progress in Cultural Heritage: Documentation, Preservation, and Protection. EuroMed 2014, v. 8740, pp. 786-801. Cham: Springer. https://doi. org/10.1007/978-3-319-13695-0_81

Benlloch-Serrano, J.; García-Cáceres, M.; Vicente, P. (2014). dFoto. Directorio de fondos y colecciones de fotografía en España. Un instrumento para la investigación y preservación de la fotografía. Latente: revista de historia y estética del audiovisual, (12), 23-31.

Boadas-Raset, J. (2016). Un tiempo nuevo en la gestión del patrimonio fotográfico. Desafíos y oportunidades. Patrimonio Cultural de España: Fotografía y patrimonio a debate, (11), 17-35. https://es.calameo.com/ read/000075335f397fa96ba44

Carrato-Mena, M. A. (2014). La aportación de España a Europeana. En: Ramos-Simón, L.F.; Arquero-Avilés; R. (coords.). Europeana: La plataforma del patrimonio cultural europeo, pp. 17-24. Madrid: Trea.

Cleverdon, C.; Mills, J.; Keen, M. (1966). Aslib Cranfield research project. Factors Determining the Performance of Indexing Systems, 2 vol. Cranfield: College of Aeronautics. https://dspace.lib.cranfield.ac.uk/ handle/1826/861

Concordia, C.; Gradmann, S.; Siebinga, S. (2010). Not just another portal, not just another digital library: es recomendable diferenciarlo por el país, y por ese motivo se incluye el término Andalucía.

4. Véase la Ley $16 / 85$ de Patrimonio Histórico Español. Dentro de la clasificación de bienes inmuebles, se distinguen ambas tipologías.

5. Máximo 960: 96 registros/página en 10 páginas; 48 registros/página en 20 páginas; 24 registros/página en 40 páginas; 12 registros/página en 80 páginas. Máximo 936: 72 registros/página en 13 páginas; 36 registros/página en 26 páginas.

6. En marzo de 2019 nos pusimos en contacto con instituciones con colecciones fotográficas del patrimonio andaluz, especialmente con el Instituto Andaluz de $\mathrm{Pa}$ trimonio Histórico (IAPH) para analizar e investigar la accesibilidad y visibilidad de dicha institución, detectando que la participación en Europeana se centraba en el proyecto Europeana Food and Drink, por lo que se recomendó promover su presencia en EuropeanaPhotography con la aportación de las colecciones fotográficas relativas a la temática fotográfica analizada en esta investigación, con el fin de que se mejore la accesibilidad y visibilidad de dichas colecciones en el ámbito europeo y su acceso universal.

A portrait of Europeana as an application program interface. IFLA Journal, 36 (1), 61-69. https://doi. org/10.1177/0340035209360764

Europeana (2018). Europeana Collections. https:// classic.europeana.eu/portal/en [Fecha de consulta: septiembre-diciembre 2017 y septiembre 2018].

EuropeanaPhotography project (2015). Web del proyecto EuropeanaPhotography. http://www.europeana-photography.eu [Fecha de consulta: 10/09/2018].

Foix, L. (2011). Patrimonio fotográfico de Catalunya en la Red. El profesional de la información, 20 (4), 378-383. https://doi.org/10.3145/epi.2011.jul.03

García-Cárceles, M. (2016). Estrategias de gestión y difusión de colecciones en el marco de las nuevas tecnologías. Patrimonio Cultural de España: Fotografía y patrimonio a debate, (11), 37-47. https://es.calameo. $\mathrm{com} / \mathrm{read} / 000075335 f 397 f a 96 \mathrm{ba} 44$

González-Pérez, A. J. (2017). Los Garzón: kalifas de la fotografía cordobesa. Córdoba: Ayuntamiento.

Junta de Andalucía (2018). Catálogo General del Patrimonio Histórico Andaluz. https://www.juntadeandalucia.es/organismos/culturaypatrimoniohistorico/areas/ bienes-culturales/catalogo-pha/consulta.html [Fecha de consulta: septiembre-diciembre 2017 y septiembre 2018].

López-Ávila, M. B. (2015). Análisis del patrimonio artístico de Granada a través de la documentación fotográfica. Revista Española de Documentación Científica, 38 (2), e087. http://dx.doi.org/10.3989/ redc. 2015.2.1167 
López-Ávila, M. B. (2018a). La accesibilidad de la fotografía sobre patrimonio en instituciones culturales. En: Valle-Rojas, C.; Linares-Herrera, M. P. (coords.). Las expresiones culturales analizadas desde la Universidad, pp. 179-187. Madrid: Tecnos-Anaya.

López-Ávila, M. B. (2018b). La evolución histórica de la fotografía en Andalucía en el siglo XIX: La ciudad y sus monumentos. En: Jiménez Pérez, E.; Del Valle Mejías, M. E.; Felipe Morales, A. (coords.), Los nuevos retos en Ciencias sociales, Artes y Humanidades, pp. 229-243. Madrid: Gedisa

Mendo-Carmona, C.; Tejada-Artigas, C. M. (2014). Europeana: un recorrido desde su nacimiento hasta nuestros días. En: Ramos-Simón, L.F.; Arquero-Avilés; R. (coords.). Europeana: La plataforma del patrimonio cultural europeo, pp. 25-44. Madrid: Trea.

Olivera-Zaldúa, M. (2015). Visibilidad de la fotografía en la Web. En: Salvador-Benítez, A. (coord.). Patrimonio fotográfico: de la visibilidad a la gestión, pp. 149-184. Gijón: Trea.

Olivera-Zaldúa, M.; Sánchez-Vigil, J. M.; Marcos-Recio, J. C. (2013). Gestión de colecciones fotográficas: Proyecto Infoco para la creación de un censo-guía de fondos y colecciones fotográficas en España, Portugal e Iberoamérica. Ibersid, 7, 117-122.

Prieto-Gutiérrez, J. J. (2014). Europeana: colección y contenidos. En: Ramos-Simón, L. F.; Arquero-Avilés; R. (coords.). Europeana: La plataforma del patrimonio cultural europeo, pp. 45-58. Madrid: Trea.

Purday, J. (2008). EuropeanaEU: integración en línea de las bibliotecas, los museos y los archivos. IV Congreso Nacional de Bibliotecas Públicas, pp. 83-93. http://travesia.mcu.es/portalnb/jspui/bitstream/10421/522/1/ com_74.pdf

Purday, J. (2012). Europeana: Digital Access to Europe's Cultural Heritage. Alexandria, 23, (2), 1-13. http:// dx.doi.org/10.7227/ALX.23.2.2

Salvador-Benítez, A.; Sánchez-Vigil, J. M. (2016). La fotografía como documento informativo en las webs de los ministerios españoles. Acceso, visibilidad, funcionalidad y políticas de uso. Revista Española de Do- cumentación Científica, 39 (2), e134. http://dx.doi. org/10.3989/redc.2016.2.1295

Sánchez-Vigil, J. M. (2011). Patrimonio fotográfico en las instituciones públicas españolas: modelos de uso y reproducción de documentos. El profesional de la información, 20 (4), 371-377. https://doi.org/10.3145/ epi.2011.jul.02

Truyen, F. (2012). EuropeanaPhotography. Deliverable D2.2: Consolidated Content List. Disponible en: http:// www.europeana-photography.eu/getFile.php?id $=218$ [Fecha de consulta: 21/05/2018].

Truyen, F.; Fresa, A. (2015). EuropeanaPhotography 2012-2015. From Retrospect to New Perspectives: a Final Report. Disponible en: http://www.photoconsortium.net/wp-content/uploads/2015/04/D1-2-EuropeanaPhotography-Final-Report_DEF_revised.pdf [Fecha de consulta: 14/05/2018].

Truyen, F.; Taes, S. (2014). Trials and Tribulations, Results and Implications. Digitizing for EuropeanaPhotography. Image \& Narrative, 15 (4), 1-12. http://www. imageandnarrative.be/index.php/imagenarrative/ article/view/660

Truyen, F.; Verbeke, D. (2015). The library as a valued partner in Digital Humanities projects: The example of EuropeanaPhotography. Art Libraries Journal, 40 (3), 28-33. https://doi.org/10.1017/ S0307472200000328

Valle-Gastaminza, F. (2014). Patrimonios visuales y audiovisuales: fotografía, sonido, cine, televisión. En: Ramos-Simón, L. F.; Arquero-Avilés; R. (coords.). Europeana: La plataforma del patrimonio cultural europeo, pp. 109-132. Madrid: Trea

Vega-Rosa, C. (2014). Guía-inventario de fondos y colecciones de fotografía de Canarias. Santa Cruz de Tenerife: Fundación General de la Universidad de La Laguna.

Yáñez-Polo, M. A. (1986). Historia de la fotografía en Andalucía. En: Yáñez-Polo, M. A.; Ortiz-Lara, L.; Holgado-Brenes, J. M. (eds.). Historia de la fotografía española, 1839-1986, pp. 41-63. Sevilla: Sociedad de Historia de la Fotografía Española. 